\title{
Clinical predictors of outcome in encephalitis
}

\author{
C R KENNEDY,${ }^{*}+\mathrm{S}$ W DUFFY,$\uparrow \mathrm{R}$ SMITH,${ }^{*}$ AND R O ROBINSON* \\ *Department of Paediatrics, Guy's Hospital, London and †Northwick Park Hospital and Clinical Research \\ Centre, Harrow, England
}

SUMmARY Twenty five patients with encephalitis were studied prospectively, and their clinical and virological features compared with outcome. Among 22 patients with laboratory confirmation of virus infection, evidence of direct effect on the central nervous system by the virus occurred significantly more often both in those with a monophasic illness compared with those with a biphasic illness, and in those with focal neurological signs localising in the cerebral hemispheres compared with those without such signs. Young age at presentation, low score on the Glasgow coma scale, disruption of oculocephalic responses, and laboratory evidence of virus infection within the central nervous system were significantly associated with poor outcome. Computed tomography results, concentrations of creatine phosphokinase BB isoenzyme in cerebrospinal fluid, and procoagulant activity in cerebrospinal fluid were not predictive of outome.

Acute encephalopathies of viral or unknown cause occur most commonly in the first decade of life with a peak incidence of $1-2 / 1000$ in the first six months of life. ${ }^{1}$ These illnesses are an important cause of handicap in the community: of those affected under the age of 3 years, $17 \%$ die and $42 \%$ are left with moderate to severe handicap (unpublished data from the British National Childhood Encephalopathy Study, 1981). Viral encephalitis is the usual clinical diagnosis but histological confirmation is rarely obtained. An association with virus infection has been shown in only $20-40 \%$ of series of consecutive patients with this diagnosis, ${ }^{1-4}$ unless the patients were highly selected. ${ }^{5}$ Because such series may have included a large number of nonviral encephalopathies, definition of the associations among aetiology, clinical features, and outcome have been largely restricted to small subgroups in which a specific virus has been implicated clinically ${ }^{6-8}$ or histologically. ${ }^{910}$ Study of the clinical features might be helpful not only in distinguishing viral from post-viral encephalitis, ${ }^{3}$ but also in establishing a provisional prognosis, because in many patients a specific virus is never identified.

We prospectively studied 32 patients with acute encephalopathies in whom initial investigation seemed to exclude a non-viral cause. An association with virus infection was shown in most of them ${ }^{11}$ and extensive immunological investigation showed no evidence of immune deficiency. ${ }^{12}$ We analysed the clinical features of 25 patients with a clinical diagnosis of encephalitis according to their prodromal illness, their neurological signs, and the site of the virus infection.

\section{Patients and methods}

Twenty nine children ( 18 boys and 11 girls) aged $0 \cdot 2$ to 13 years (median 3.8 years; quartiles 1.3 and 6.5 years) and three adults aged 22 to 38 years were studied prospectively because (a) they had either acute depression of conscious level or acute onset of focal neurological signs that had not been precipitated by a seizure and (b) no non-infectious or bacterial causes were found on initial investigation. Thus patients with either suspected viral encephalitis or unexplained encephalopathy were studied. Patients with nuchal rigidity but without focal neurological signs or obvious decrease in conscious level (suggesting uncomplicated viral meningitis) did not fulfil the criteria for admission. The patients were drawn from the following sources: paediatric neurology $(n=15)$; paediatric infectious diseases $(n=7)$; general paediatrics $(n=7)$; and adult medicine $(n=3)$. Seventeen were referred to a specialised centre from the hospital to which they were first admitted.

The history was taken and repeated neurological examinations performed and recorded on a standardised form by one of us (CRK). The examination was repeated at least daily for the first four days in 
hospital and at least weekly thereafter until discharge. Conscious level was assessed using the Glasgow coma scale as modified for children. ${ }^{13}$ Questionnaires about the childs' behaviour before the illness were completed by parents and teachers when the child was entered in the study. The management of seizures and raised intracranial pressure, and the indications for the use of acyclovir were standardised. Clinical circumstances led to deviation from this policy in only one patient (case 27).

Full blood counts, examination of the cerebrospinal fluid and biochemical analysis of the serum were done by the hospital laboratory services. The virological methods used and criteria for defining active virus infection have been reported elsewhere. ${ }^{11}$ EEG and computed tomography of the brain were classified according to the consultant's written report. The BB isoenzyme of creatine phosphokinase (CPK-BB) was measured in cerebrospinal fluid by $\mathrm{Dr}$ RJ Thompson, Cambridge, England. The ratio of the activated and nonactivated derivatives of plasma clotting factor VII (VIIc:VIIt ratio), an indirect measure of thromboplastin activity, was measured in cerebrospinal fluid and plasma by the coagulation laboratory at the Clinical Research Centre, Northwick Park.

Outcome was evaluated by one of us (CRK) seven to eight months after the patient's discharge from hospital using neurological examination and, for children under the age of 8 years, the Griffiths mental development scales. In addition, children over the age of 5 years were tested by an experienced clinical psychologist (RS) using the revised version of the Weschler intelligence scales for children (WISC-R). Behaviour was assessed in children aged 18 months to 5 years using the Richman behaviour checklist, ${ }^{14}$ and in the children over the age of 5 using the Rutter A and B scale questionnaires for parents and teachers, respectively. ${ }^{15}$ Outcome was assessed in all surviving patients except for one boy (case 20) whose mother did not wish to have him evaluated further. $\mathrm{He}$ seemed to have made a full and rapid recovery and was placed in outcome category 5 in the analysis.

Outcome was expressed in five categories ranked from 1 to 5 constructed from three variables: neurological examination, developmental quotient, and behaviour. Categories were assigned as follows: $1=$ dead or development quotient $<40 ; 2=$ development quotient $40-80$ plus major neurological signs or behaviour problem; $3=$ development quotient 40-80 without major neurological signs or behaviour problem; $4=$ development quotient $>80$ plus major neurological signs or behaviour problem, and $5=$ development quotient $>80$ without major neurological signs or behaviour problem.
Major neurological problems were defined as those that interfered with function to the extent that the patient required assistance with activities of daily living. A behaviour problem was defined as a problem perceived by the parent or teacher, together with a rise in score in the behaviour questionnaire by more than five points over that before the illness to a value on the Richman or Rutter scale showing an established association with behavioural problems.

The outcome thus expressed was compared with clinical and laboratory variables measured at the time of the neurological illness. Acute phase variables were compared with category of outcome by regression analysis on continuous effects, and analysis of variance on factorial effects. Although this entailed the treatment of categories of outcome as continuous, we preferred it to a $\chi^{2}$ analysis as the marginal totals were too small for such an analysis to be valid. Furthermore, the necessary assumption of a normally distributed residual variation was supported by a $p$ value of 0.68 in a Shapiro and Wilk W test for non-normality performed on the residuals. Tests for the significance of associations between acute phase variables and category of outcome were done using the $\mathrm{F}$ test. A two tailed Fisher's exact test was used to assess the significance of all other differences.

\section{Results}

DURATION OF SYMPTOMS AND DIAGNOSIS

The median delay between the onset of any symptom and entry into the study was nine days (quartiles five and 15 days). Half the patients were entered within three days of the onset of neurological symptoms or signs (quartiles two and five days). One patient (case 26) was exceptional in having a neurological illness for 30 days prior to entry. There was no significant difference between the duration of preceding symptoms in patients with monophasic illnesses compared with those with biphasic illnesses.

From the history, clinical examination, biochemical and neuroradiological investigations, but without the results of virological investigations, patients were placed in the following diagnostic categories: encephalitis $(n=25)$; haemorrhagic shock and encephalopathy $(n=2)^{16}$; Reye's syndrome $(n=1)$; cerebrovascular accident with respiratory infection, $(n=1)$; and non-infectious cause $(n=3)$ (moyamoya disease $n=1$, haemangioma at the craniocervical junction $n=1$, intracerebral haemorrhage $n=1$ ). All results reported below refer exclusively to the 25 patients with encephalitis.

The diagnosis of encephalitis was made on clinical 
rather than histological grounds, but laboratory confirmation of virus infection either within the central nervous system $(n=11)$ or outside the central nervous system $(n=11)$ was subsequently obtained in all but three patients (table 1). ${ }^{11}$ Of these three patients, one (case 26) had a subacute illness the symptoms of which included a persistent high fever and a rash; the neurological prodrome of 30 days and hospital stay of three months were unusually prolonged. The case histories of the other two patients (cases 27 and 28) were also suggestive of infection. Delay in presentation was consistently associated with lower yields from virological investigation in this study ${ }^{11}$ and seemed the most likely explanation for our failure to identify the causal agent in these two patients who presented after 10 and 11 days of symptoms, respectively. We have therefore considered these three patients together with the other patients with a clinical diagnosis of encephalitis in subsequent analyses.

\section{CLINICAL AND LABORATORY FEATURES OF PATIENTS WITH ENCEPHALITIS}

Details of symptoms, clinical examination, neuroradiological investigation, the infective agent, and the outcome are given individually for each patient in tables 2 and 3 .

Eighteen patients had a prodromal illness that was not neurological (respiratory in nine, respiratory and gastrointestinal in one, rash in six, myalgia in one, and fever alone in one). The remaining seven patients had exclusively neurological symptoms. Clear signs of recovery from the prodromal illness before the onset of the neurological illness (a biphasic illness) were seen in 12 patients, although only four had an interval of entirely normal health between the two illnesses. Among the 22 patients with laboratory confirmation of virus infection, a significantly larger number of those with a monophasic illness had laboratory evidence of virus infection within the central nervous system than of those with a biphasic illness (eight of 10 and three of $12 ; \mathrm{p}<0 \cdot 03)$.

Focal neurological signs were seen in $20(80 \%)$. These were divided into three categories: cranial nerve signs, ataxia, and the combination of rigidity, spasticity, tremor or weakness of a distribution which suggested that the brain rostral to the brain stem and cerebellum was affected'hemispheric signs'. Among the 22 patients with laboratory confirmation of virus infection, those with hemispheric signs were significantly more likely to have laboratory evidence of virus infection within the central nervous system than those without such signs (nine of 12 and two of $10 ; p<0.03$ ).

Significant disturbance of consciousness (modi

Table 1 Laboratory evidence of infection in 25 patients with clinical diagnosis of encephalitis

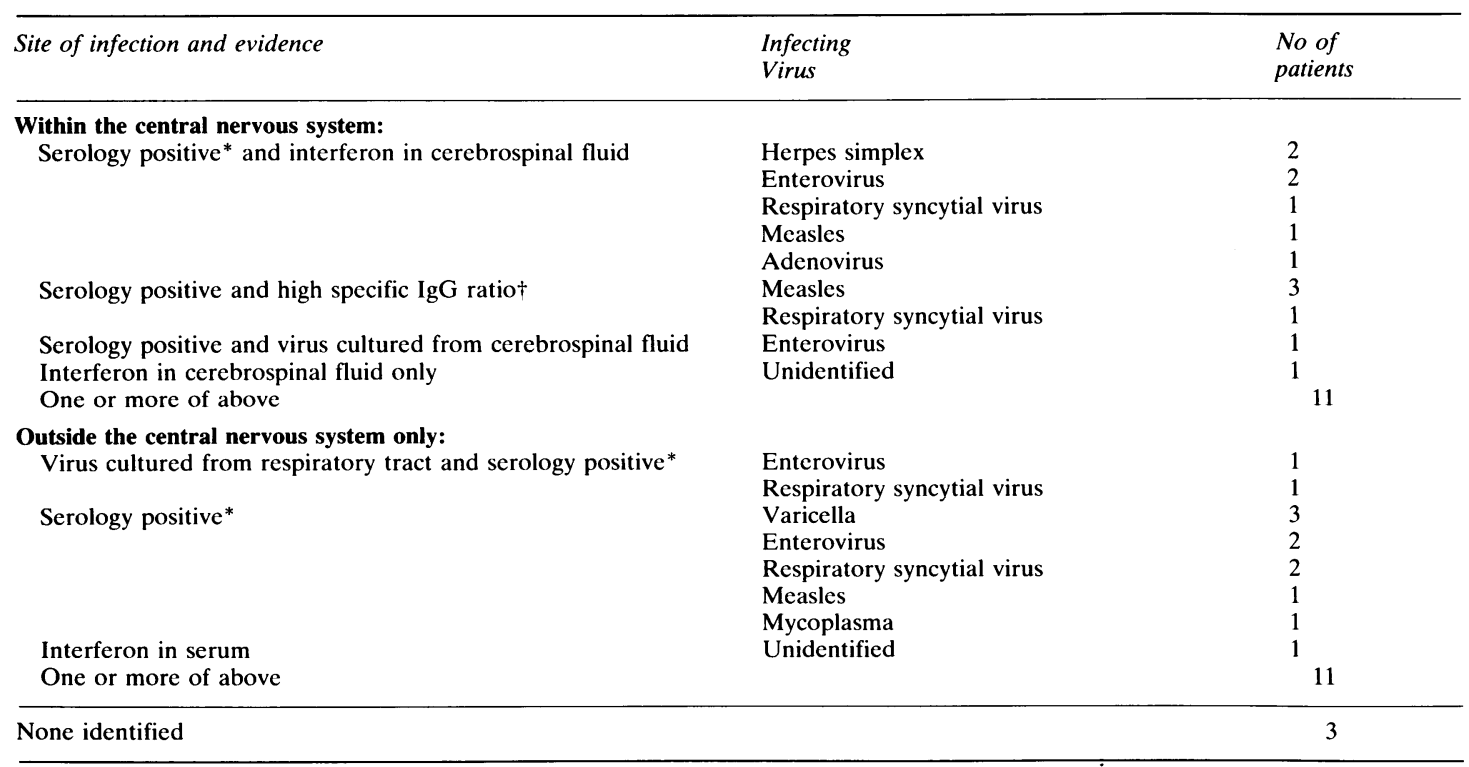

${ }^{*}$ Fourfold rise in IgG between paired sera, or high IgG and IgM concentrations in acute serum.

+ Specific IgG ratio $=$ Specific cerebrospinal fluid $\times$ total serum IgG/Specific serum IgG $\times$ total cerebrospinal fluid $\operatorname{IgG}$. 
fied Glasgow coma scale score of $<14$ ) was seen in eight of $12(67 \%)$ of those with a biphasic illness and 11 of $13(85 \%)$ of those with a monophasic illness. The score fell below 11 in $13(52 \%)$ and below six in three $(12 \%)$. Disruption of oculocephalic responses, normally induced by the application of cold water to the external auditory meatus, was seen in two patients. An increase in intracranial pressure was suspected clinically in five, and measured as $>20$ $\mathrm{mm} \mathrm{Hg}$ in three patients including one infant

Table 2 Clinical features and outcome in patients with encephalitis and laboratory evidence of virus infection of the central nervous system.

\begin{tabular}{|c|c|c|c|c|c|c|c|c|c|c|}
\hline \multirow{2}{*}{$\begin{array}{l}\text { Case } \\
\text { No }\end{array}$} & \multirow{2}{*}{$\begin{array}{l}\text { Infecting } \\
\text { virus }\end{array}$} & \multirow[t]{2}{*}{ Age } & \multirow{2}{*}{$\begin{array}{l}\text { Days of } \\
\text { symp- } \\
\text { toms }\end{array}$} & \multirow{2}{*}{$\begin{array}{l}\text { Monophasic } \\
\text { or biphasic } \\
\text { illness }\end{array}$} & \multirow{2}{*}{$\begin{array}{l}\text { White } \\
\text { cells } \\
\text { in cerebro- } \\
\text { spinal } \\
\text { fluid }\end{array}$} & \multirow{2}{*}{$\begin{array}{l}\text { High }^{*} \\
\text { albumin } \\
\text { ratio }\end{array}$} & \multirow{2}{*}{$\begin{array}{l}\text { Admission } \\
\text { coma scale } \\
\text { score }\end{array}$} & \multirow{2}{*}{$\begin{array}{l}\text { Neurological } \\
\text { examination }\end{array}$} & \multicolumn{2}{|l|}{ Follow up } \\
\hline & & & & & & & & & $\begin{array}{l}\text { Neuro- } \\
\text { logical } \\
\text { signs }\end{array}$ & $\begin{array}{l}\text { Develop- } \\
\text { mental } \\
\text { quotient }\end{array}$ \\
\hline 1 & Echovirus & $6 \cdot 5$ & 4 & Monophasic & No & No & 12 & Hemispheric & Normal & 108 \\
\hline 2 & Echovirus & $11 \cdot 0$ & 3 & Monophasic & Yes & No & 14 & Brain stem & Normal & 107 \\
\hline 4 & $\begin{array}{l}\text { Herpes } \\
\text { simplex }\end{array}$ & 38 & 7 & Monophasic & Yes & Yes & 13 & Hemispheric & Normal & 119 \\
\hline 5 & $\begin{array}{l}\text { Herpes } \\
\text { simplex }\end{array}$ & $1 \cdot 6$ & 6 & Monophasic & No & No & 6 & Hemispheric & Hemiplegia & 76 \\
\hline 6 & Measles & $6 \cdot 5$ & 10 & Monophasic & Yes & Yes & 14 & Hemispheric & Normal & $78+$ \\
\hline 7 & Measles & $3 \cdot 8$ & 18 & Monophasic & No & No & 11 & Hemispheric & Minor & 76 \\
\hline 8 & Measles & $12 \cdot 3$ & 18 & Biphasic & No & Yes & 14 & Hemispheric & Minor & $68+$ \\
\hline 9 & $\begin{array}{l}\text { Respiratory } \\
\text { syncytial } \\
\text { virus }\end{array}$ & $13 \cdot 0$ & 4 & Monophasic & Yes & Yes & 11 & Hemispheric & Minor & 119 \\
\hline 10 & Adenovirus & $1 \cdot 3$ & 7 & Monophasic & No & Yes & 7 & Hemispheric & Minor & 76 \\
\hline 11 & (?)Influenza A & $3 \cdot()$ & 10 & Biphasic & Yes & No & 10 & Hemispheric & Normal & 127 \\
\hline
\end{tabular}

${ }^{*} \mathrm{CSF}=$ serum ratio $>3 \mathrm{SD}$ above reference mean, $\dagger=$ severe behaviour problem

Table 3 Clinical features and outcome in patients with encephalitis either with virus infection outside central nervous system only (case Nos 12-22) or without laboratory confirmation of infection (case Nos 23-25)

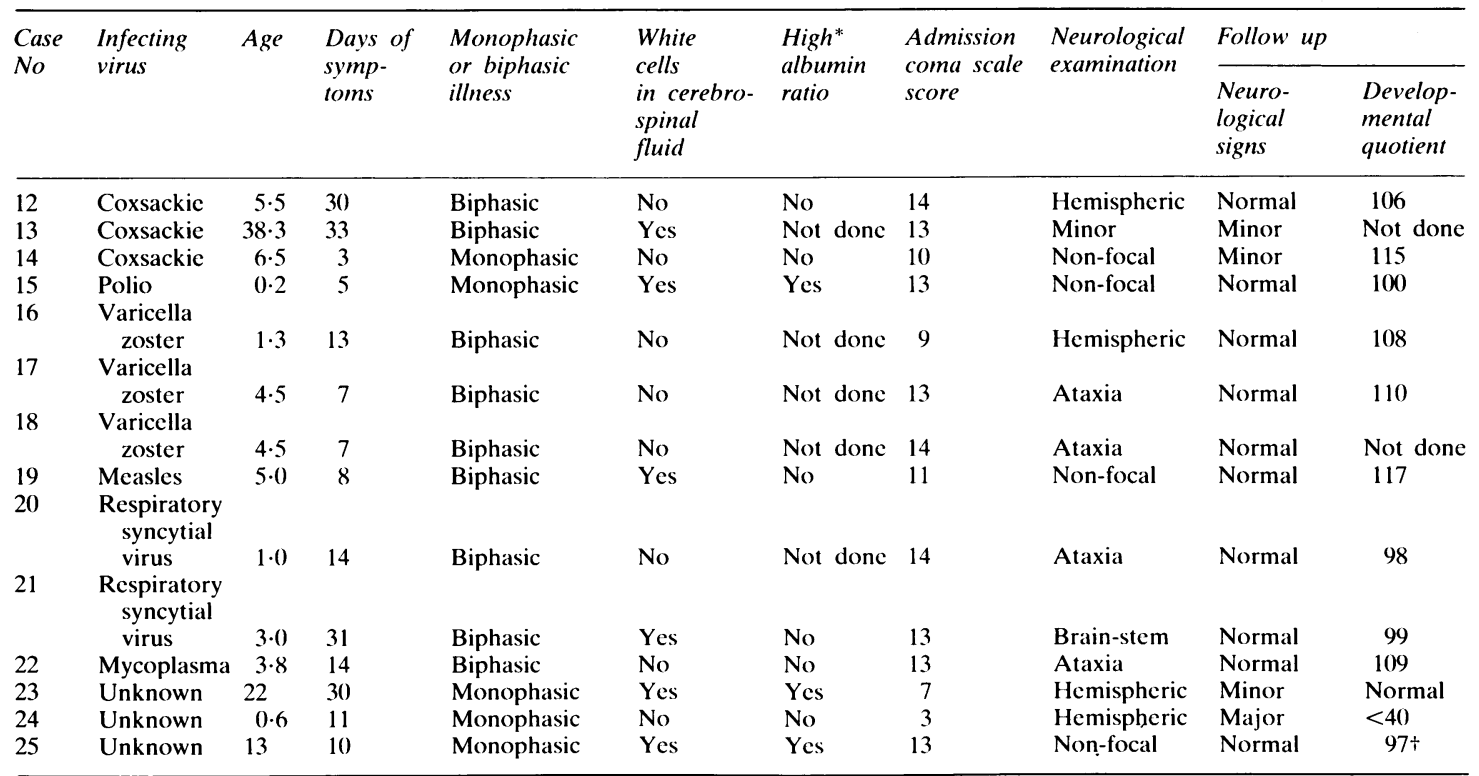

$*=\mathrm{CSF}$ :serum ratio $>3 \mathrm{SD}$ above reference mean, $\dagger=$ severe behaviour problem 
without any specific clinical signs of raised intracranial pressure (case 24).

Transudation of protein into the cerebrospinal fluid was suggested by an albumin ratio of greater than three standard deviations above a reference mean for children and young adults in nine of the 20 patients who had albumin concentrations measured in both cerebrospinal fluid and serum. Albumin ratios were significantly higher in patients with infection of the central nervous system than in those with infection outside the central nervous system alone $\left(\mathrm{n}_{1}=6, \mathrm{n}_{2}=9, \mathrm{~T}_{2}=30, \mathrm{p}<0.05\right.$, Wilcoxon two sample test).

The EEG was abnormally slow in 18 of 19 tested patients (highest frequency $>\theta$ in seven, $\theta$ in eight, and $<\theta$ in three). Abnormalities were seen on computed tomography in nine of 19 tested patients (focal low attenuation in six, diffuse low attenuation of white matter in two, and enlarging ventricles in one). Abnormalities were not always detectable on the first examination.

\section{OUTCOME AND ITS CORRELATION WITH CLINICAL}

FEATURES AT PRESENTATION

Outcome categories were assigned. The distribution of acute phase variables that were significantly associated with outcome are shown by category for all 25 patients with a clinical diagnosis of encepha-

Table 4 Acute phase factors associated with outcome in 25 patients with a clinical diagnosis of encephalitis

\begin{tabular}{|c|c|c|c|c|c|c|}
\hline \multirow[t]{2}{*}{$\begin{array}{l}\text { Acute phase } \\
\text { factor }\end{array}$} & \multicolumn{5}{|c|}{$\begin{array}{l}\text { No of patients in } \\
\text { outcome categories }\end{array}$} & \multirow[t]{2}{*}{$\begin{array}{l}p \\
\text { Value }\end{array}$} \\
\hline & 1 & 2 & 3 & 4 & 5 & \\
\hline \multicolumn{7}{|c|}{$\begin{array}{l}\text { Age (excluding } \\
\text { three adults): }\end{array}$} \\
\hline$<3$ years & 2 & 1 & 2 & 1 & 2 & \multirow[t]{2}{*}{$0 \cdot 02$} \\
\hline$>3$ years & 0 & 2 & 0 & 1 & 11 & \\
\hline \multicolumn{7}{|c|}{$\begin{array}{l}\text { Minimum modified } \\
\text { Glasgow coma } \\
\text { scale score: }\end{array}$} \\
\hline$<5$ & 1 & 1 & 0 & 0 & 1 & \multirow{3}{*}{$0 \cdot 04$} \\
\hline $5-9$ & 1 & 1 & 2 & 0 & 6 & \\
\hline $10-15$ & 0 & 1 & 0 & 2 & 9 & \\
\hline \multicolumn{7}{|l|}{$\begin{array}{l}\text { Oculocephalic } \\
\text { responses }\end{array}$} \\
\hline Normal & 0 & 3 & 2 & 2 & 16 & \multirow{2}{*}{$0 \cdot 0004$} \\
\hline Abnormal & 2 & () & 0 & 0 & 0 & \\
\hline \multicolumn{7}{|c|}{$\begin{array}{l}\text { Laboratory } \\
\text { evidence of } \\
\text { viral infection: }\end{array}$} \\
\hline CNS & 1 & 3 & 2 & 0 & 5 & \multirow{3}{*}{$0 \cdot 02^{*}$} \\
\hline non-CNS & 0 & 0 & 0 & 1 & 10 & \\
\hline none & 1 & () & 0 & 1 & 1 & \\
\hline
\end{tabular}

*comparison between central nervous system and other two categories combined. litis in table 4. A poor outcome was associated with low scores on the modified Glasgow coma scale $(p<0 \cdot 05)$, age of less than 3 years $(p<0 \cdot 02$ excluding adults whose inclusion increased the significance of the finding), abnormality of oculocephalic responses $(\mathrm{p}<0 \cdot 001)$, and laboratory evidence of virus infection within the central nervous system $(p<0 \cdot 02)$. After correcting for coma scale score on admission, or for age, the other three factors remained significantly associated with outcome. If developmental quotient was used as a measure of outcome in survivors the same associations persisted, suggesting that the associations were not artefacts of the chosen system of categorising outcome.

Outcome seemed to be associated with only one of the immunological measurements at the time of the acute illness; if patients were divided into those who developed sequelae and those who did not, the cerebrospinal fluid:serum albumin concentration ratio was significantly higher in those with sequelae $\left(\mathrm{n}_{1}=9, \mathrm{n}_{2}=9, \mathrm{~T}_{2}=59 \cdot 5, \quad \mathrm{p}<0.05\right.$, Wilcoxon two sample test).

In addition, both low scores on the coma scale on admission and a greater degree of slowing on EEG were associated with poor outcome, although these were not statistically significant. Abnormalities on computed tomography were not associated with outcome, and there was no correlation between outcome and concentrations in the cerebrospinal fluid of either CPK-BB isoenzyme (13 patients), or the VIIc:VIIt ratio (19 patients), although cerebrospinal fluid was sampled from patients in all categories.

\section{Discussion}

We have taken encephalitis caused by infection with any one of several common viruses to be a single entity for the purpose of analysing the prognostic value of certain clinical features. Although such an analysis ignores differences in pathogenesis associated with different viruses,${ }^{17}$ it has the advantage of being clinically applicable to the $60-80 \%$ of encephalitides in which a specific agent is not identified by routine virology. ${ }^{1-4}$

For the minority in which a virus can be identified, the prognoses associated with different agents are distinguishable but with rare exceptions (such as rabies, Lassa fever, and eastern equine encephalitis) similar to one another; mortality varies by less than $15 \%$ among encephalitis complicating infection with rubella $(20 \%)$ or measles $(9 \%-27 \%),{ }^{6}{ }^{18}$ adenovirus 7a $(14 \%),{ }^{19}$ and herpes simplex type 1 encephalitis treated with acyclovir $(19 \%-31 \%))^{9}{ }^{10}$ The incidence of sequelae is $25-40 \%$ both in these encephalitides and in those with a lower mortality caused 
by enteroviruses in infancy, ${ }^{20}$ mumps, ${ }^{7}$ and chickenpox. ${ }^{68}$ The prognosis of encephalitis after infancy caused by enteroviruses, influenza viruses $A$ and $B,{ }^{21}{ }^{22}$ parainfluenza viruses 1,2 , and 3 , and respiratory syncytial virus, is ill defined. Thus the prognosis of childhood encephalitides associated with common viruses may be determined more readily from the clinical features of the illness than from knowledge of the identity of the virus.

It is commonly thought that the virus either directly invades the brain or triggers an immunologically mediated illness one to two weeks after an infection which may not have affected the central nervous system directly. The presence of a particular virus does not mean that the neurological illness must be early or late; measles, ${ }^{23}$ influenza, ${ }^{21} 22$ varicella ${ }^{22}{ }^{2},{ }^{6}{ }^{24}$ and herpes simplex ${ }^{25}$ may lead to either type of illness. In the present study enterovirus and respiratory syncytial virus infections were found both within the central nervous system and confined to sites other than the central nervous system, confirming that both types of encephalitis may be caused by the same agent. Furthermore, it is not clear how often both viral and immunologically mediated diseases may coexist, because most patients do not come to necropsy. We therefore feel that subdivision of encephalitis on clinical grounds is in theory as reasonable as subdivision by causal agent, and potentially as useful in practice.

Kennard and Swash ${ }^{3}$ reported that mortality was lower $(5 \%$ and $20 \%)$ but morbidity higher $(42 \%$ and $22 \%$ ) among patients with an interval of normal health between the first illness and the neurological illness than among those without such an interval. Two clinicovirological groupings emerge from the present study: the first consists of a monophasic illness with neurological signs of impairment of the cerebral hemispheres and laboratory evidence of direct involvement of the central nervous system by a viral infection, and the second of a biphasic illness without focal signs of impairment of the cerebral hemispheres, and with evidence of viral infection only at sites other than the central nervous system. In this series encephalitis was associated with mortality or morbidity in almost half the patients with viral infection of the central nervous system, but not in those with evidence of infection by the same viruses confined to sites other than the central nervous system at the time of their neurological illness.

Focal neurological signs were associated with a poor prognosis in two earlier series if present ${ }^{2}$ or 'marked', ${ }^{3}$ but were not more precisely associated with virology or outcome. Both studies were retrospective and concerned mainly adult patients.
In the present prospective study that was predominantly of children the presence of focal neurological signs was a marker for infection of the central nervous system and, therefore, of a higher probability of long term sequelae. This may also have been true for the earlier series.

In hypoxic or ischaemic encephalopathy the level of consciousness, length of coma, and presence of abnormalities of oculocephalic responses or of EEG may predict outcome. ${ }^{26} 27$ Of these, conscious level and abnormal oculocephalic responses were also predictive of outcome in the present study. A significant association between the severity of the EEG abnormality and outcome might have emerged if larger numbers had been studied, but the weakness of this association and the relative lack of predictive value of the length of coma may be a reflection of the fact that the symptoms are reversible when caused by a virus, but not when caused by hypoxia or ischaemia. The same association between conscious level and outcome has been reported in encephalitis caused by measles, varicella zoster, rubella, ${ }^{6}$ and herpes simplex type $I^{10}{ }^{10}$ An association between seizures and poor outcome reported by other authors was not confirmed by our results.

An important finding in this study was that young age at presentation was related to poor outcome. Indeed, most of the morbidity was among the youngest patients with less than half (three of 7) of patients under the age of 2 years recovering uneventfully. An independent effect of age is suggested by its persistent association with outcome even after adjusting for either conscious level on admission or the presence of laboratory evidence of virus infection within the central nervous system.

The association between transudation of albumin into the cerebrospinal fluid and evidence of viral infection of the central nervous system is of interest. Our observations do not, however, enable us to determine whether this is a cause or a consequence of breakdown of the blood brain barrier.

This series did not confirm the association between pleocytosis and outcome, which has previously been reported. ${ }^{2} 3$ Furthermore, in spite of earlier more encouraging reports on small mixed groups of patients with viral meningitis, bacterial meningitis, or encephalitis, ${ }^{28} 29$ signs of neuronal damage, concentrations of $\mathrm{CPK}-\mathrm{BB}$ isoenzyme, and the VIIc:VIIt ratio in the cerebrospinal fluid were neither sensitive nor specific in the present study. This may reflect either release from areas of the central nervous system where damage does not find clinical expression, or the unavoidable variation in the timing of sampling in relation to the onset of the illness. Computed tomography during the acute 
illness proved, unlike EEG, only moderately sensitive in the detection of encephalitis (as previously reported for herpes simplex encephalitis). ${ }^{30}$ In addition, the presence of abnormalities on computed tomography was not of predictive value; good and bad outcome was seen in patients with normal pictures, and in those with unilateral necrosis or diffuse low attenuation of white matter.

In conclusion a monophasic illness prior to hospital admission, and the presence of focal neurological signs suggesting disease of the cerebral hemispheres may indicate a greater likelihood of direct effect on the central nervous system by the virus in suspected viral or post-viral encephalitis in childhood. This in turn is associated with long term sequelae. With a uniform policy of management, the outcome of these illnesses seems to be predictable by the clinical features of presentation at a young age, low conscious level, abnormal oculocephalic responses, and laboratory evidence of direct effect on the central nervous system by the virus; all these exercise unfavourable effects. These factors should be taken into account in the evaluation of methods of treatment. Further studies are needed to establish the stability of these factors in a larger sample.

This study was generously supported by grants from the Medical Research Council and Action Research for the Crippled Child. We thank Drs WA Hendrickse, AM Kaiser, FJ Kirkham, SD Levin, MM Liberman, the late WC Marshall, BGR Neville, Professor RJ Robinson, and Dr HB Valman for their help in recruiting patients to the study; Drs KWG Heathfield, P Jaffe, and CS Ogg for permission to study their patients; and the staff of the Northwick Park Clinical Research Centre coagulation laboratory for measuring cerebrospinal fluid procoagulant activity.

\section{References}

${ }^{1}$ Wang D, Bortolussi R. Acute viral infection of the CNS in children: an eight year review. Can Med Assoc J 1981;125: 585-9.

2 Miller JD, Ross CAC. Encephalitis-a four year survey. Lancet $1968 ; \mathbf{i}: 1121-6$.

${ }^{3}$ Kennard C, Swash M. Acute viral encephalitis. Its diagnosis and outcome. Brain 1981;104:129-48.

${ }^{4}$ Koskiniemi M, Manninen V, Vaheri A, Sainio K, Eistola P, Karli P. Acute encephalitis. Acta Med Scand 1981;209:115-20.

${ }^{5}$ Meyer HM Jr, Johnson RT, Crawford IP, Dascomb HE, Rogers NG. Central nervous system syndromes of "viral" etiology. A study of 713 cases. Am J Med 1960;29:334-7.

6 Miller HG, Stanton JB, Gibbons JL. Para-infectious encephalomyelitis and related syndromes. $Q J$ Med 1956;25:427-505.

${ }^{7}$ Koskiniemi I, Donner M, Pettay O. Clinical appearances and outcome in mumps encephalitis in children. Acta Paediatr Scand 1983;72:603-9.

8 Johnson RT, Griffiths DE, Gendelman HE. Postinfectious encephalomyelitis. Seminars in Neurology 1985;5:180-90.
${ }^{9}$ Skoldenberg B, Forsgren M, Alestig K, et al. Acyclovir versus vidaribine in herpes simplex encephalitis. Randomized multicentre study in consecutive Swedish patients. Lancet 1984;ii: 707-11.

10 Whitley RJ, Alford CA, Hirsch MS, et al. Vidarabine versus acyclovir therapy in herpes simplex encephalitis. $N$ Engl J Med 1986;314:144-9.

"Kennedy CR, Chrzanowska K, Robinson RO, Tyrrell DAJ, Valman HB, Webster ADB. A major role for viruses in acute childhood encephalopathy. Lancet 1986;i:988-91.

12 Kennedy CR, Bird D, Chrzanowska K, Stephens S, Webster ADB. The pathogenesis of acute virus-associated encephalopathies: a prospective study of immunological mechanisms. Clin Immunol Immunopathol 1987;42:218-28.

13 Gordon NS, Fois A, Jacobi G, Minns RA. Seshia SS. The management of the comatose child. Neuropediatrics 1984;14: 3-5.

${ }^{14}$ Richman N, Stephenson JE, Graham PJ. Prevalence of behaviour problems in three year old children: an epidemiological study in a London borough. J Child Psychol Psychiatry 1975:16:277-87

15 Rutter M. A children's behaviour questionnaire for teachers: preliminary findings. J Child Psychol Psychiatry 1967;8:1-11.

${ }^{16}$ Levin M. Hjelm M, Kay JDS, et al. Haemorrhagic shock and encephalopathy: a new syndrome with a high mortality in young children. Lancet 1983;ii:64-7.

17 Johnson RT. Selective vulnerability of neural cells to viral infection. Brain 1980:103:447-72.

${ }^{18}$ Boughton CR. Morbilli in Sydney Part II. Neurological sequelac of morbilli. Med J Aust 1964;2:908-15

${ }^{19}$ Simila S, Jouppila R, Salmi A, Pohjohnen R. Encephalomyelitis in children associated with adenovirus type 7 epidemic. Acta Paediatr Scand 1970:59:310-6.

${ }^{20}$ Sells CJ, Carpenter RL, Ray CG. Sequelae of central nervous system enterovirus infections. $N$ Engl J Med 1975;293:1-4.

${ }^{21}$ Flewett TH, Hoult JG. Influenzal encephalopathy and postinfluenzal encephalitis. Lancet 1958;ii:11-15.

22 Hoult JG, Flewett JG. Influenzal encephalopathy and postinfluenzal encephalitis. Histological and other observations. $\mathrm{Br}$ Med J 1960;i: $1847-50$.

${ }^{23}$ Kipps A. Dick G, Moodie JW. Measles and the central nervous system. Lancet 1983;ii:1406-10.

${ }^{24}$ Norris FJ Jr, Leonards R, Calanchini PR, Calder CD. Herpes zoster meningoencephalitis. J Infect Dis 1970;122:135-8.

${ }^{25}$ Koenig H, Rabinowitz SG, Day E, Miller V. Post-infectious encephalomyelitis after successful treatment of herpes simplex encephalitis with adenosine arabinoside: ultrastructural observations. N Engl J Med 1979;300:1089-93.

26 Pampiglione G, Harden A. Resuscitation after cardiocirculatory arrest. Lancet 1968;i:1261-4.

27 Seshia SS. Seshia MMK, Sachdeva RK. Coma in childhood. Dev Med Child Neurol 1977;19:614-28.

${ }^{28}$ Gracber JE. Stuart MJ. Spinal fluid procoagulant activity: a sensitive indicator of CNS damage. Lancet 1978;ii:285-8.

29 Briem H, Lindquist L, Lundbergh P, Sego E, Skoldenberg B. Creatine kinase isoenzyme $\mathrm{BB}$ in cerebrospinal fluid from patients with meningitis and encephalitis. $J$ Infect Dis 1983:148:179-80.

3) Dutt MK, Johnston IDA. CT and EEG in Herpes simplex encephalitis. Arch Neurol 1982;39:99-102.

Correspondence and requests for reprints to Dr CR Kennedy, Lecturer in Child Health, Southampton General Hospital, Southampton S09 4XY, England.

Received 15 May 1987 